\title{
Operation Characteristics Improvement of Linear Synchronous Motor with Half-Wave Rectified Self Excitation
}

\author{
Tadashi Hirayama*, Tsuyoshi Higuchi, Takashi Abe, Jun Oyama \\ Department of Electrical and Electronic Engineering, Faculty of Engineering, Nagasaki University, Japan \\ 1-14 Bunkyo-machi, Nagasaki, 852-8521 Japan
}

\begin{abstract}
This paper presents a new control method in order to improve the operation characteristics for a novel linear synchronous motor with half-wave rectified self excitation. First, we propose the new control method by addition of the reluctance thrust across full speed range for the novel linear synchronous motor. Then, the operation characteristics of the proposed control method are theoretically estimated and compared with the previous control method.
\end{abstract}

\section{INTRODUCTION}

A linear synchronous motor (LSM) has been used in industry application such as transportation and transfer system [1]. Because the efficiency is high, a permanent magnet type LSM is widely used. If a d-axis current large enough to offset against the permanent magnet flux is provided, the field weakening operation becomes possible. However, a copper loss caused by the d-axis current decreases the efficiency.

In the pervious paper, we proposed a novel LSM with halfwave rectified self excitation [2]. The field winding is short circuited through a diode and the armature winding is conventional 3-phase windings. If the amplitude of balanced 3phase currents is modulated by an alternating wave with bias frequency, the produced magnetomotive force pulsates at bias frequency and moves at synchronous velocity. This pulsating magnetomotive force induces the electromotive force with bias frequency in the field winding. The field excitation is obtained by rectifying the electromotive force with the diode of the field winding. As the field flux of the novel LSM is controllable by only varying amplitude of the armature current, the field weakening operation is performed easily. We designed and built the experimental machine [3] [4] and measured the basic characteristics [5] [6]. And, we proposed a maximum thrustper-current control by addition of the reluctance thrust at the constant thrust region [7] and a maximum thrust-per-voltage control in order to expand the operating range [8]. However, it had a problem with the switching of these control method because the reluctance thrust was not used in the maximum thrust-per-voltage control.

This paper presents a new control method by addition of the reluctance thrust across full speed range. We propose, first, the control method of the field weakening operation and the maximum thrust-per-voltage control with the reluctance thrust.
Then, the operation characteristics are theoretically shown by calculation and compared with the previous control method.

\section{LSM WITH HALF-WAVE RECTIFIED SELF EXCITATION}

\section{A. Structure of the Novel LSM}

Figure 1 shows the structure of the LSM with half-wave rectified self excitation. The LSM consists of followings;

(1) A LSM mover whose field winding is short circuited through a diode.

(2) A LSM stator with conventional 3-phase armature windings.

(3) A control system that operates based on half-wave rectified self excitation principle.

(4) A PWM inverter.

\section{B. Principle of Self Excitation and Thrust Generation}

The following 3-phase currents, which synchronized with the mover position, are supplied to the 3-phase stator windings;

$$
\left.\begin{array}{l}
i_{a}=A_{f}(t) \sin \theta+\sqrt{2} I_{t} \cos \theta \\
i_{b}=A_{f}(t) \sin (\theta-2 \pi / 3)+\sqrt{2} I_{t} \cos (\theta-2 \pi / 3) \\
i_{c}=A_{f}(t) \sin (\theta-4 \pi / 3)+\sqrt{2} I_{t} \cos (\theta-4 \pi / 3)
\end{array}\right\} .
$$

where, $\theta=\pi x / \tau, x$ : mover position, $\tau$ : pole pitch.

The first term of (1) is excitation current, which varies with sine of the mover position and whose amplitude is modulated by a function $A_{f}(t)$. Where, $A_{f}(t)$ is a triangular wave function with the effective value of $I_{f}$ and bias frequency $\omega_{b}$. The second term of (1) is thrust current component.

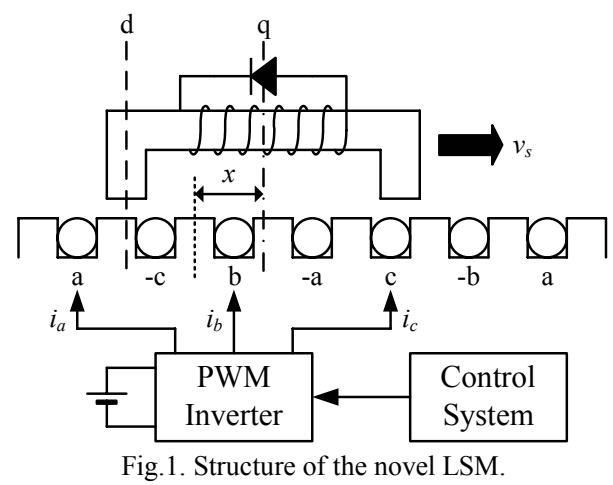




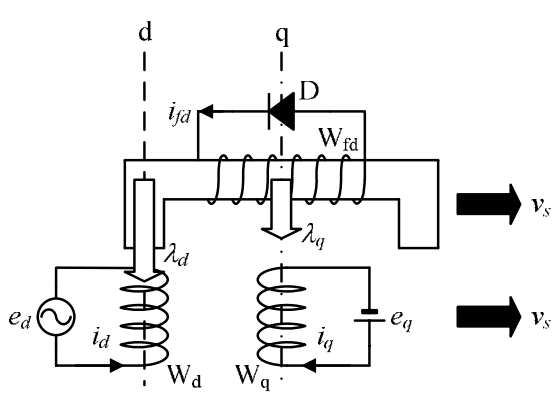

Fig. 2. Equivalent model on the dq-axis.

Figure 2 shows the dq-axis model of the novel LSM. The daxis current $i_{d}$ and q-axis current $i_{q}$ become;

$$
\left.\begin{array}{rl}
i_{d} & =\sqrt{\frac{3}{2}} A_{f}(t) \\
i_{q} & =\sqrt{3} I_{t}
\end{array}\right\} .
$$

Then, flux linkage $M_{f d} i_{d}$ is generated on the mover d-axis. The field current $i_{f d}$ is induced in the field winding to keep the maximum value of the flux. The flux linkage $\lambda_{f d}$ is the sum of two flux linkages; $M_{f d} i_{d}$ provided by the stator excitation current and $L_{f d} i_{f d}$ by the mover field current. As a result, the following flux linkages are generated on the dq-axis windings.

$$
\left.\begin{array}{l}
\lambda_{d}=L_{d} i_{d}+M_{f d} i_{f d} \\
\lambda_{q}=L_{q} i_{q} \\
\lambda_{f d}=M_{f d} i_{d}+L_{f d} i_{f d}
\end{array}\right\}
$$

where, $\lambda_{d}, \lambda_{q}$ : dq-axis flux linkage, $\lambda_{f d}$ : flux linkage with the field winding, $L_{d}, L_{q}:$ dq-axis self inductance, $L_{f d}$ : field winding self inductance, $M_{f d}$ : mutual inductance.

If the time constant of the field winding is large enough, the flux linkage with the field winding $\lambda_{f d}$ is kept constant.

The thrust $F$ is obtained from the following equation;

$$
F=\frac{\pi}{\tau}\left(\lambda_{d} i_{q}-\lambda_{q} i_{d}\right) .
$$

Fig. 3 shows above-mentioned currents, flux, and thrust waveforms. Though a pulsating component exists in the thrust as shown in Fig. 3, practically it is not serious problem by choosing the bias frequency suitably.

\section{BASIC EQuations OF THE NOVEL LSM}

The novel LSM has the saliency of $L_{d}>L_{q}$. For using the reluctance thrust due to the saliency, the following direct current $I_{r}$ is added to the d-axis current $i_{d}$ of (2).

$$
i_{d}=\sqrt{\frac{3}{2}} A_{f}(t)+\sqrt{3} I_{r}
$$

Assuming that the winding resistance equals zero, then the average thrust $F_{\text {avg }}$ is derived from (4) as follows;

$$
F_{\text {avg }}=\frac{\pi}{\tau}\left\{3 \sqrt{\frac{3}{2}}(1-\sigma) L_{d} I_{f} I_{t}+3\left(L_{d}-L_{q}\right) I_{t} I_{r}\right\} .
$$

where, $\sigma$ : leakage coefficient.
$A_{f}(t)$
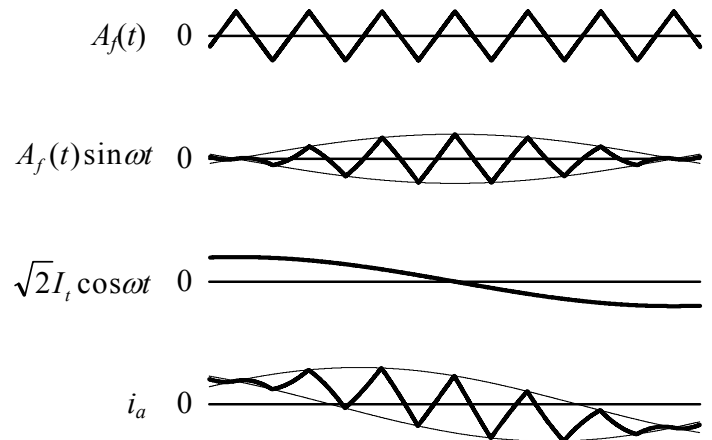

$i_{d}$
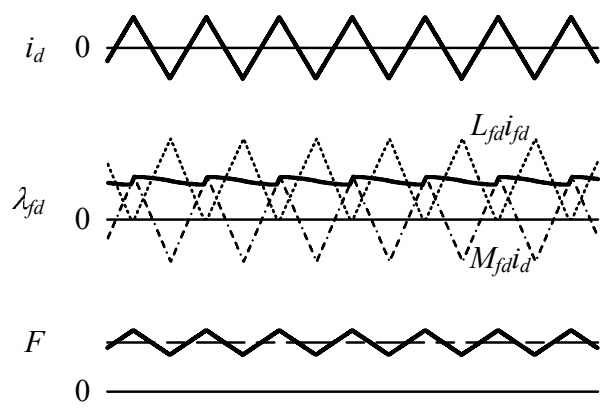

Fig. 3. Current, flux, and thrust waveform.

The first term of (6) is average thrust generated by half-wave rectified self excitation principle. The second term of (6) is the reluctance thrust. Also, the effective value of the armature current $I$ and the terminal voltage $V_{o}$, which the winding resistance is assumed to be zero, are given as the following equations and confined to those limit values.

$$
\begin{aligned}
& I=\sqrt{I_{t}^{2}+\frac{1}{2} I_{f}^{2}+I_{r}^{2}} \leq I_{n} \\
& V_{o}=\sqrt{\frac{9}{2}\left\{\omega(1-\sigma) L_{d} I_{f}\right\}^{2}+\frac{3}{2}\left(\omega \sigma L_{d} I_{f}\right)^{2}+3\left(\frac{\sqrt{6}}{\pi} \omega_{b} \sigma L_{d} I_{f}\right)^{2} *} \\
& \text { *+3 } \sqrt{6}\left(\omega L_{d}\right)^{2}(1-\sigma) I_{f} I_{r}+3\left(\omega L_{d} I_{r}\right)^{2}+3\left(\omega L_{q} I_{t}\right)^{2} \leq V_{\text {om }}
\end{aligned}
$$

Where, $\omega$ is the synchronous angular velocity, $I_{n}$ is the rated current, $V_{o m}$ is the voltage limit and given from the following equation;

$$
V_{o m}=V_{n}-\sqrt{3} r_{a} I_{n} .
$$

where, $V_{n}$ : rated voltage, $r_{a}$ : armature winding resistance.

\section{Control Method Utilizing Reluctance Thrust}

In the novel LSM, the condition of $I_{r}$ for the maximum thrust-per-current control by addition of the reluctance thrust is given as follows [7];

$$
I_{r}=-\frac{\sqrt{6} \frac{M_{f d}^{2}}{L_{f d}}}{4\left(L_{d}-L_{q}\right)} I_{f}+\sqrt{\frac{3\left(\frac{M_{f d}^{2}}{L_{f d}}\right)^{2}}{8\left(L_{d}-L_{q}\right)^{2}} I_{f}^{2}+I_{t}^{2}} .
$$




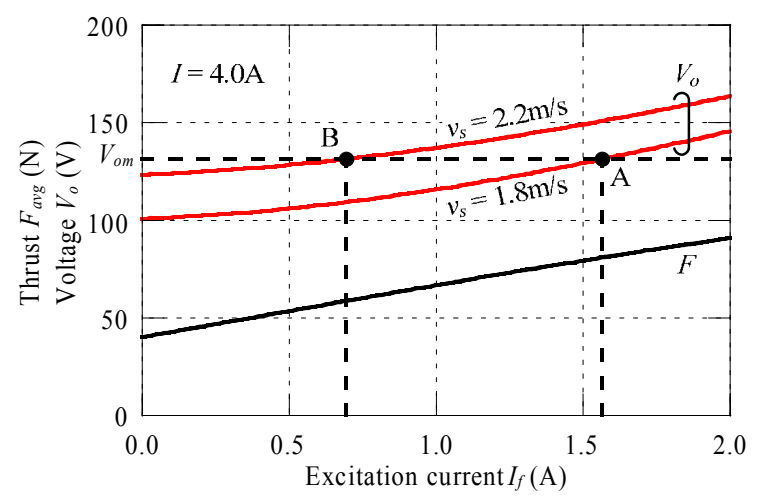

Fig. 4. Effects of $I_{f}$ on the thrust and the voltage.

TABLE I

RATED VALUES, WINDING RESISTANCES AND INDUCTANCES

\begin{tabular}{|ll|l|}
\hline Item & & Value (Unit) \\
\hline Rated current & $I_{n}$ & $4(\mathrm{~A})$ \\
\hline Rated voltage & $V_{n}$ & $200(\mathrm{~V})$ \\
\hline Armature winding resistance & $r_{a}$ & $9.9(\Omega)$ \\
\hline Field winding resistance & $r_{f d}$ & $14.9(\Omega)$ \\
\hline d-axis inductance & $L_{d}$ & $0.170(\mathrm{H})$ \\
\hline q-axis inductance & $L_{q}$ & $0.138(\mathrm{H})$ \\
\hline Mover self inductance & $L_{f d}$ & $1.783(\mathrm{H})$ \\
\hline Mutual inductance & $M_{f d}$ & $0.306(\mathrm{H})$ \\
\hline
\end{tabular}

In the constant thrust region, $I_{f}$ is fixed and the maximum thrust-per-current control is applied. We theoretically examine a new control method by addition of the reluctance thrust across full speed range.

\section{A. Field Weakening Operation}

First, the field weakening operation utilizing the reluctance thrust is examined. Fig. 4 shows effects of $I_{f}$ on the thrust and the voltage at the armature current $I=4.0 \mathrm{~A}$ when $I_{r}$ is controlled by (10). For characteristic calculation, the rated values and motor parameters of the experimental machine are used. These parameters are shown in Table I.

In the field weakening operation, $I_{f}$ is controlled so as to confine $V_{o}$ to $V_{o m}$ according to the velocity as shown in point A and B of Fig. 4.

\section{B. Maximum Thrust-per-Voltage Control}

Next, the maximum thrust-per-voltage control by addition of the reluctance thrust is examined. In the maximum thrust-pervoltage control, we maximize the ratio of the thrust to the voltage with keeping the voltage to its limit value and properly controlling the armature current. The maximum thrust-pervoltage control is realized by controlling according to $I_{f}, I_{r}$, and $I_{t}$ obtained from the following equations.

$$
\left.\begin{array}{l}
V_{o}=V_{o m} \\
\partial F_{a v g}\left(V_{o}, \omega, I_{f}, I_{r}\right) / \partial I_{f}=0 \\
\partial F_{a v g}\left(V_{o}, \omega, I_{f}, I_{r}\right) / \partial I_{r}=0
\end{array}\right\}
$$

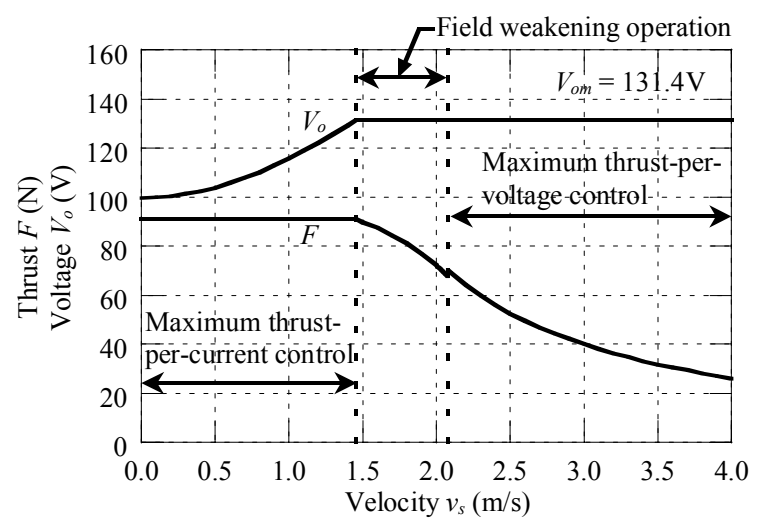

(a) Thrust and voltage characteristics.

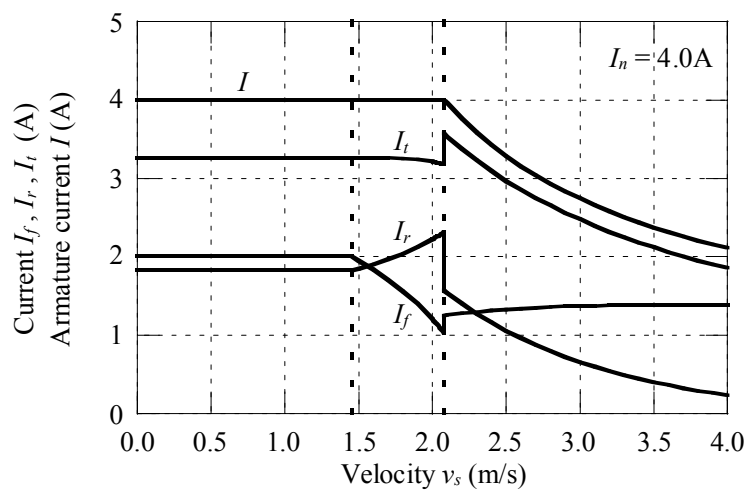

(b) Current characteristics.

Fig. 5. Calculation results of operation characteristics.

Figure 5 shows the calculation results of the operation characteristics. The calculation conditions are as follows; $I_{f}$ at constant thrust region is $2.0 \mathrm{~A}, \omega_{b}$ is $50 \mathrm{~Hz}, V_{\text {om }}$ is $131.4 \mathrm{~V}$.

As shown in Fig. 5, the field weakening operation is applied at $v_{s}=1.45 \mathrm{~m} / \mathrm{s}$, the maximum thrust-per-voltage control is applied at $v_{s}=2.08 \mathrm{~m} / \mathrm{s}$. It is confirmed that the control method is well switched from the maximum thrust-per-current control to the field weakening operation. However, there is a problem that the thrust, $I_{f}, I_{r}$ and $I_{t}$ are discontinuous when the control method is switched from the field weakening operation to the maximum thrust-per-voltage control. In order to solve this problem, we propose the renewed maximum thrust-per-voltage control.

\section{Renewed Maximum Thrust-per-Voltage Control}

In the renewed maximum thrust-per-voltage control, $I_{r}$ is controlled by (10). Fig. 6 shows the effects of $I_{f}$ on the thrust and the armature current at the voltage $V_{o}=131.4 \mathrm{~V}$ and $v_{s}=$ $3.0 \mathrm{~m} / \mathrm{s}$. In the renewed maximum thrust-per-voltage control, $I_{f}$ and the armature current are controlled so as to maximize the thrust as shown in point $\mathrm{C}$ of Fig. 6 .

Figure 7 shows the calculation results of the operation characteristics when the renewed maximum thrust-per-voltage control is applied. As shown in Fig. 7, the maximum thrust-pervoltage control is applied at $v_{s}=2.01 \mathrm{~m} / \mathrm{s}$. It is confirmed that 


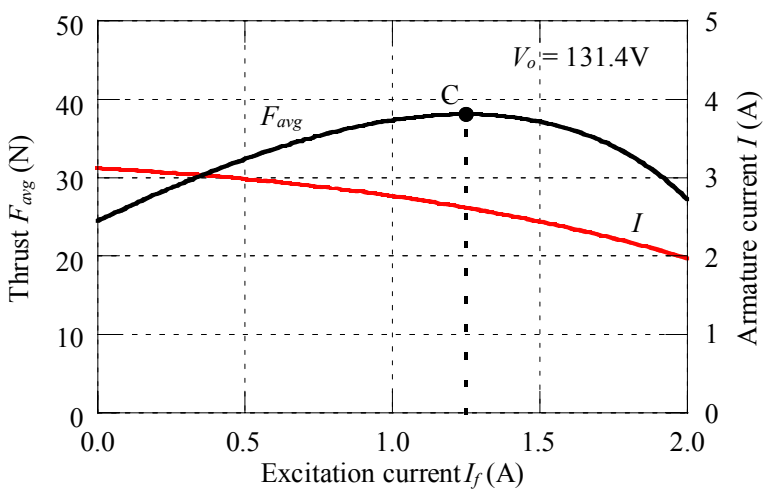

Fig. 6. Effects of $I_{f}$ on the thrust and the armature current.

the control method is well switched from the field weakening operation to the maximum thrust-per-voltage control by applying the renewed maximum thrust-per-voltage control.

Figure 8 shows the comparison of the thrust characteristics of the proposed control method with that of the previous control method [8]. In these characteristic calculations, the same voltage limit, current limit, and motor parameters are used. It is confirmed that the thrust characteristics of proposed control method is improved in comparison with the previous control method.

\section{CONCLUSIONS}

In this paper, we proposed a new control method by addition of the reluctance thrust across full speed range. By applying the proposed control method, the control method was well switched from the maximum thrust-per-current control to the field weakening operation and from the field weakening operation to the maximum thrust-per-voltage control. Also, we confirmed that the thrust characteristics of proposed control method were improved in comparison with the previous control method.

\section{REFERENCES}

[1] M. Karita, "Trends of linear drive technologies in industry applications," T. IEEE Japan, Vol. 119-D, No. 3, pp. 276-278, March 1993.

[2] J. Oyama, T. Higuchi, T. Abe, H. Tanaka, and E. Yamada, "A novel linear synchronous motor with half-wave rectified self excitation," The Third International Symposium on Linear Drives for Industry Applications, Japan, pp. 144-148, October 2001.

[3] J. Oyama, T. Higuchi, T. Abe, S. Kubota, and T. Hirayama, "Principle and analysis of a novel linear synchronous motor with half-wave rectified self excitation," Proc. of the 17th International Conference on Magnetically Levitated Systems and Linear Drives, No.PP07109, pp. 16, September 2002.

[4] J. Oyama, T. Higuchi, T. Abe, T. Hirayama, and S. Takahashi, "The mover design for thrust ripple reduction of half-wave rectified selfexcitation type linear synchronous motor," Proc. of the 2004 Japan Industry Application Society Conference, Japan, Vol. 3, pp. 295-298, September 2004.

[5] J. Oyama, T. Higuchi, T. Abe, and T. Hirayama, "Basic characteristics of linear synchronous motor with half-wave rectified self-excitation," Proc. of the 2003 Japan Industry Application Society Conference, Japan, Vol. 3, pp. 265-268, August 2003.

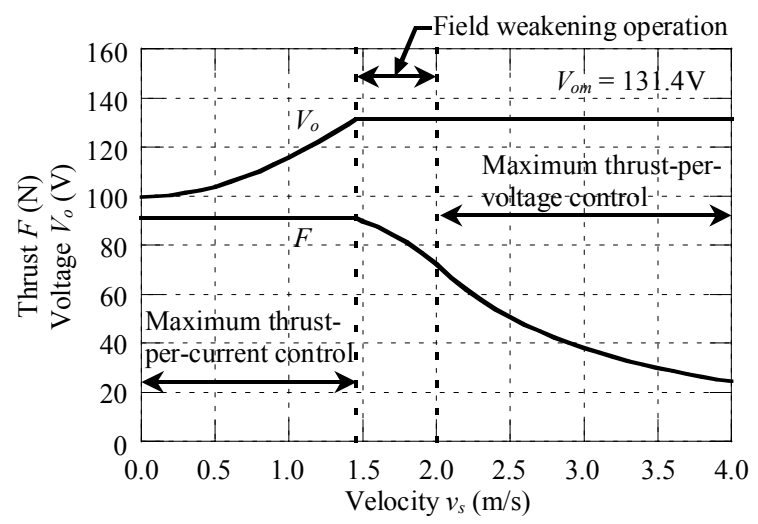

(a) Thrust and voltage characteristics.

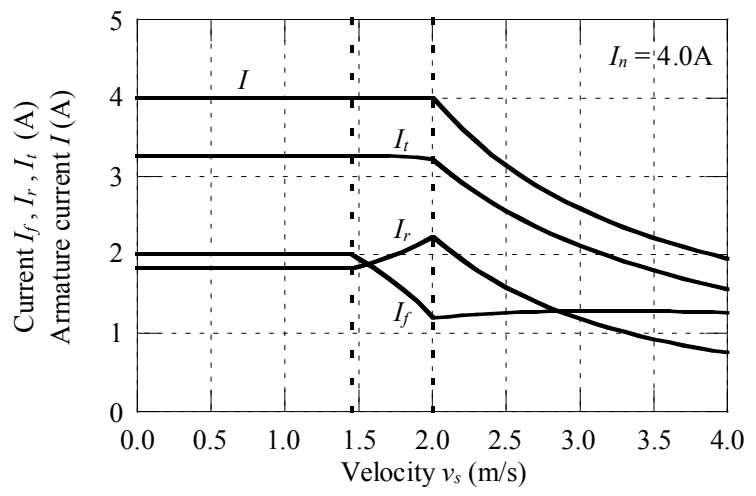

(b) Current characteristics.

Fig. 7. Operation characteristics under the renewed control method.

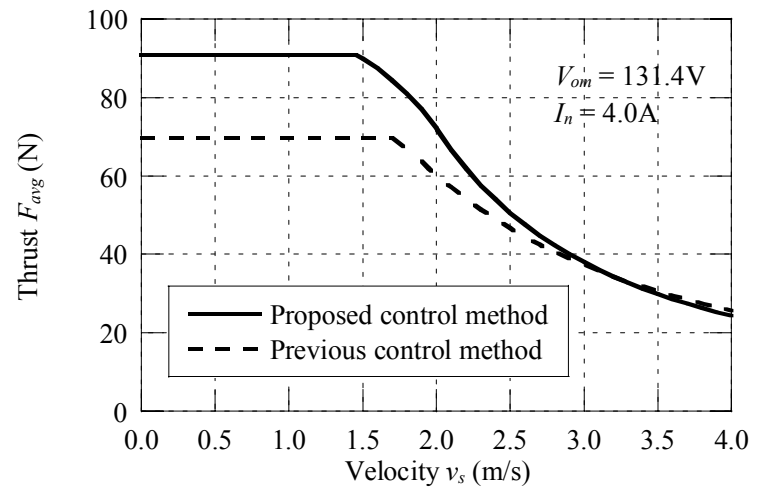

Fig. 8. Comparison of the thrust characteristics of the proposed control method with that of the previous control method.

[6] T. Hirayama, J. Oyama, T. Higuchi, and T. Abe, "Thrust characteristic of half-wave rectified self excitation type linear synchronous motor with a mover designed for thrust ripple reduction," Proc. of the 2004 Japan Industry Application Society Conference, Japan, Vol. 3, pp. 291-294, September 2004.

[7] T. Hirayama, J. Oyama, T. Higuchi, and T. Abe, "Maximum thrust control of linear synchronous motor with half-wave rectified self excitation at constant thrust region," Proc. of the 2006 JIAS Conf., Japan, Vol. 3, No. 3-3, pp. III/147-III/150, August 2006.

[8] J. Oyama, T. Higuchi, T. Abe, and T. Hirayama, "Control method of linear synchronous motor with half-wave rectified self excitation at high speed region," Proc. of the 2006 International Conference on Electrical Machines and Systems, Japan, No. LS3B-3, November 2006. 